\title{
Association Between Parity and Low Bone Density Among Postmenopausal Korean Women
}

\author{
Eunsun Seo', Yongrong Lee', Hyeon Chang Kim ${ }^{1,2}$ \\ ${ }^{1}$ Department of Preventive Medicine, Yonsei University College of Medicine, Seoul, Korea; ${ }^{2}$ Department of Public Health, Yonsei University Graduate \\ School, Seoul, Korea
}

Objectives: Low bone density (LBD) in the postmenopausal period has long been a pervasive public health concern; however, the association between parity and LBD has yet to be fully elucidated. Thus, we investigated the association between parity and LBD in postmenopausal Korean women.

Methods: This study used baseline data from 1287 Korean postmenopausal women aged 40 years or older enrolled in the Cardiovascular and Metabolic Diseases Etiology Research Center community-based cohort study conducted in Korea from 2013 to 2017. The main exposure was parity (nullipara, 1, 2, 3+). The main outcome was LBD, including osteopenia and osteoporosis, based on bone mineral density measured using quantitative computed tomography of the lumbar spine (L1-2).

Results: The mean age of participants was 57.1 years, and the median parity was 2. Of the 1287 participants, 594 (46.2\%) had osteopenia and 147 (11.4\%) had osteoporosis. No significant difference in the prevalence of LBD was found between nullipara and parous women, whereas higher parity was associated with a higher risk of LBD among parous women; the adjusted odds ratio (95\% confidence interval) for the presence of LBD was 1.40 (0.97 to 2.02) for a parity of 2 and 1.95 (1.23 to 3.09 ) for a parity of 3 relative to a parity of 1 .

Conclusions: Women who have given birth multiple times may be at greater risk of bone loss after menopause; therefore, they should be a major target population for osteoporosis prevention.

Key words: Parity, Bone density, Osteoporosis, Osteopenia

\section{INTRODUCTION}

Postmenopausal women are considered to be at high risk of developing osteoporosis, as estrogen deficiency accelerates bone turnover with net bone loss [1]. The prevalence of osteo-

Received: March 26, 2021 Accepted: June 10, 2021

Corresponding author: Hyeon Chang Kim Department of Preventive Medicine, Yonsei University College of Medicine, 50-1 Yonsei-ro, Seodaemun-gu, Seoul 03722, Korea E-mail: hckim@yuhs.ac

This is an Open Access article distributed under the terms of the Creative Commons Attribution Non-Commercial License (https://creativecommons.org/licenses/by$\mathrm{nc} / 4.0 /$ ) which permits unrestricted non-commercial use, distribution, and reproduction in any medium, provided the original work is properly cited. penia and osteoporosis among Korean women aged 50 years and older is $48.7 \%$ and $38.0 \%$, respectively [2]. Reducing the population burden of fractures requires paying more attention to women with osteopenia, because over half of fragility fractures in the general population arise in these individuals [3]. The bone mineral density (BMD) at every skeletal site in Korean men and women was found to be significantly lower than that of United States participants when comparing the results of the 2008-2011 Korea National Health and Nutrition Examination Survey (KNHANES) and the 2007-2009 United States National Health and Nutrition Examination Survey [2]. It has been estimated that the residual lifetime probability of osteoporosis-related fractures in 50-year-old Korean women is 
$59.5 \%$ [4]. Therefore, with the aging Korean population, the assessment of postmenopausal osteopenia and osteoporosis is particularly important.

Among the factors related to low bone density (LBD), parity and lactation remain controversial. Some studies have suggested that in postmenopausal women, a history of prolonged breastfeeding is an independent risk for osteoporosis $[5,6]$. Conversely, other studies have reported that the effect of breastfeeding on LBD in the postmenopausal period is not significant. It has been reported that BMD almost fully recovers after the restart of menstruation and weaning of lactation $[7,8]$, and that spinal BMD significantly increased over time even when lactation continued for more than 6 months [7].

However, the effect of parity on the risk of LBD is not clear in the literature. Pregnancy and childbirth are factors that can lead to hormonal changes in the postpartum period, as well as throughout pregnancy. Parity also exerts a non-hormonal effect on BMD because lifestyle (e.g., nutrition, sleep, smoking, drinking, and physical activity) changes that can affect BMD occur during the parenting process following childbirth. Previous studies have reported diverse results regarding the association between parity and LBD. Some studies have reported a positive association between parity and the risk of osteoporosis or osteoporotic fracture [1], but others have not $[9,10]$. Another study reported that parous women had significantly higher BMD in the total hip than nullipara women, but there was no difference in the femoral neck or lumbar spine [11].

Thus, we investigated whether parity was associated with LBD among middle-aged postmenopausal women.

\section{METHODS}

\section{Participants and Data Source}

This cross-sectional study was conducted using baseline data from the Cardiovascular and Metabolic Diseases Etiology Research Center (CMERC) study, a community-based cohort study conducted in Korea. The CMERC dataset includes data obtained from questionnaire interviews, physical examinations, neuropsychological testing, electrocardiography, a laboratory blood workup, and quantitative computed tomography (QCT). The CMERC baseline data included a sample of 2634 middle-aged (30-64 years) women with an obstetric history and BMD measured using QCT to examine associations between parity and LBD, including osteopenia and osteoporosis. Of these, 367 participants younger than 40 years and 500 premenopausal wom- en were excluded. Participants who were on hormone replacement $(n=395)$ or steroid therapy $(n=4)$, which could affect $B M D$, were also excluded. Four participants with missing QCT results and 77 participants with missing covariate data were excluded. Thus, 1287 participants were included in the final analysis.

\section{Measurements}

Dual X-ray absorptiometry (DXA) and QCT are the most common tools for measuring BMD [12]. Compared to DXA, QCT is less affected by surrounding tissues and may avoid the overestimation of BMD on DXA that is associated with spinal degeneration, abdominal aortic calcification, and other sclerotic lesions [13]. When using QCT, spinal volumetric BMD (vBMD) is known to be more sensitive than BMD measurements at other sites [12]. Thus, we analyzed the QCT-measured spinal vBMD of $\mathrm{L} 1$ to $\mathrm{L} 2$ trabecular bone as the outcome.

The participants were scanned using a Somatom Definition AS+ 128-channel computed tomography (CT) scanner (Siemens Healthcare, Forchheim, Germany), a Somatom Sensation 64-channel CT scanner (Siemens Healthcare), or a General Electric LightSpeed VCT scanner (GE Medical Systems, Milwaukee, WI, USA) at $120 \mathrm{kVp}$ and $150 \mathrm{mAs}$, using a $50-\mathrm{cm}$ scan field of view. A liquid dipotassium phosphate $\left(\mathrm{K}_{2} \mathrm{HPO}_{4}\right)$ phantom (Model 3; Mindways Software, Austin, TX, USA) was included in each scan to prevent scanner drift and to calculate the VBMD. Images obtained of the lumbar spine (L1-2) were reconstructed with a standard body reconstruction algorithm at 3-mm slice thickness, with an in-plane pixel size of $512 \times 512$ and a display field-of-view of $250 \mathrm{~mm}$. All scanned data were analyzed using QCTPro software (Mindways Software). Lumbar trabecular vBMD was calculated as the average $\mathrm{VBMD}$ of the $\mathrm{L} 1$ and $\mathrm{L} 2$ trabecular bones.

We defined LBD as including osteopenia and osteoporosis. According to the official positions of the International Society for Clinical Densitometry 2019 and American College of Radiology 2018 revised guidelines [14], we defined LBD as BMD $<120 \mathrm{mg} / \mathrm{cm}^{3}$. Osteoporosis was defined as a lumbar trabecular BMD $\leq 80 \mathrm{mg} / \mathrm{cm}^{3}$ or as taking anti-osteoporosis medication.

Height was measured within $0.1 \mathrm{~cm}$ using a stadiometer while the participant was standing in an upright position (Jenix, Seoul, Korea). Body weight was determined within $0.1 \mathrm{~kg}$ using an electronic scale (CAS, Seongnam, Korea). Body mass index (BMI) was calculated as body weight in kilograms divid- 
Table 1. General characteristics of the study population according to parity

\begin{tabular}{|c|c|c|c|c|c|c|c|}
\hline \multirow{2}{*}{ Characteristics } & \multirow{2}{*}{$\begin{array}{l}\text { Nulliparous } \\
(\mathrm{n}=40)\end{array}$} & \multirow{2}{*}{$\begin{array}{l}\text { Parous } \\
(n=1247)\end{array}$} & \multirow{2}{*}{$p$-value } & \multicolumn{3}{|c|}{ Parous ( $n=1247$ ) } & \multirow{2}{*}{$p$-value } \\
\hline & & & & $1(n=153)$ & $2(n=873)$ & $3+(n=221)$ & \\
\hline Age (y) & $56.4 \pm 5.1$ & $57.1 \pm 3.9$ & 0.380 & $56.6 \pm 4.2$ & $56.9 \pm 3.8$ & $58.4 \pm 4.0$ & $<0.001$ \\
\hline Body mass index $\left(\mathrm{kg} / \mathrm{m}^{2}\right)$ & $23.4 \pm 3.1$ & $23.7 \pm 3.0$ & 0.433 & $23.7 \pm 3.4$ & $23.7 \pm 2.9$ & $24.0 \pm 2.9$ & 0.235 \\
\hline Parity & $0[0-0]$ & $2[2-2]$ & $<0.001$ & $1.0 \pm 0.0$ & $2.0 \pm 0.0$ & $3.1 \pm 0.3$ & $<0.001$ \\
\hline No. of pregnancies & $0[0-1]$ & $3[3-4]$ & $<0.001$ & $2.3 \pm 1.1$ & $3.5 \pm 1.2$ & $4.7 \pm 1.4$ & $<0.001$ \\
\hline Postmenopausal period (y) & $7.0[2.5-10.0]$ & $6.0[3.0-9.0]$ & 0.859 & $7.3 \pm 5.2$ & $6.8 \pm 4.9$ & $7.8 \pm 5.4$ & 0.016 \\
\hline No. of abortions & $0[0-1]$ & $1[1-2]$ & $<0.001$ & $1.3 \pm 1.1$ & $1.4 \pm 1.2$ & $1.6 \pm 1.4$ & 0.090 \\
\hline PA (MET score) & & & 0.973 & & & & 0.632 \\
\hline Inactive & $10(25.0)$ & $304(24.4)$ & & $32(20.9)$ & $216(24.7)$ & $56(25.3)$ & \\
\hline Minimally active & $19(47.5)$ & $603(48.4)$ & & $76(49.7)$ & $415(47.5)$ & $112(50.7)$ & \\
\hline Health enhancing PA & $11(27.5)$ & $340(27.3)$ & & $45(29.4)$ & $242(27.7)$ & $53(24.0)$ & \\
\hline Education level & & & 0.075 & & & & $<0.001$ \\
\hline Middle school or less & $4(10.0)$ & $314(25.2)$ & & $33(21.6)$ & $188(21.5)$ & $93(42.1)$ & \\
\hline High school & $22(55.0)$ & $569(45.6)$ & & $73(47.7)$ & $424(48.6)$ & $72(32.6)$ & \\
\hline University or beyond & $14(35.0)$ & $364(29.2)$ & & $47(30.7)$ & $261(29.9)$ & $56(25.3)$ & \\
\hline Working status & & & 0.295 & & & & 0.002 \\
\hline Working & $23(57.5)$ & $612(49.1)$ & & $87(56.9)$ & $438(50.2)$ & $87(39.4)$ & \\
\hline Non-working & $17(42.5)$ & $635(50.9)$ & & $66(43.1)$ & $435(49.8)$ & $134(60.6)$ & \\
\hline Household income & & & 0.994 & & & & 0.666 \\
\hline Low & $5(12.5)$ & $157(12.6)$ & & $17(11.1)$ & $114(13.1)$ & $26(11.8)$ & \\
\hline Middle-low & $24(60.0)$ & $745(59.7)$ & & $92(60.1)$ & $512(58.7)$ & 141 (63.8) & \\
\hline Middle-high/high & $11(27.5)$ & $345(27.7)$ & & $44(28.8)$ & $247(28.3)$ & $54(24.4)$ & \\
\hline Smoking & & & $<0.001$ & & & & 0.173 \\
\hline No & $34(85.0)$ & 1203 (96.5) & & $145(94.8)$ & 841 (96.3) & $217(98.2)$ & \\
\hline Ever & $6(15.0)$ & $44(3.5)$ & & $8(5.2)$ & $32(3.7)$ & $4(1.8)$ & \\
\hline Drinking & & & 0.693 & & & & 0.032 \\
\hline No & $15(37.5)$ & $430(34.5)$ & & $39(25.5)$ & $308(35.3)$ & 83 (37.6) & \\
\hline Yes & $25(62.5)$ & 817 (65.5) & & $114(74.5)$ & $565(64.7)$ & $138(62.4)$ & \\
\hline Marital status & & & $<0.001$ & & & & 0.004 \\
\hline Married & $13(32.5)$ & 1055 (84.6) & & 116 (75.8) & 756 (86.6) & 183 (82.8) & \\
\hline Unmarried & $27(67.5)$ & $192(15.4)$ & & $37(24.2)$ & $117(13.4)$ & $38(17.2)$ & \\
\hline Diabetes & & & 0.935 & & & & 0.211 \\
\hline No & $38(95.0)$ & $1181(94.7)$ & & $147(96.1)$ & $830(95.1)$ & 204 (92.3) & \\
\hline Yes & $2(5.0)$ & $66(5.3)$ & & $6(3.9)$ & $43(4.9)$ & $17(7.7)$ & \\
\hline Hypertension & & & 0.199 & & & & 0.319 \\
\hline No & $35(87.5)$ & $987(79.2)$ & & $126(82.4)$ & $693(79.4)$ & $168(76.0)$ & \\
\hline Yes & $5(12.5)$ & $260(20.9)$ & & $27(17.7)$ & $180(20.6)$ & $53(24.0)$ & \\
\hline Thyroid disease & & & & 0.185 & & & 0.481 \\
\hline No & 33 (82.5) & 1112 (89.2) & & $136(88.9)$ & $774(88.7)$ & 202 (91.4) & \\
\hline Yes & $7(17.5)$ & $135(10.8)$ & & $17(11.1)$ & $99(11.3)$ & $19(8.6)$ & \\
\hline Chronic kidney disease & & & 0.720 & & & & 0.576 \\
\hline No & $40(100)$ & $1243(99.7)$ & & $153(100)$ & 870 (99.7) & 220 (99.6) & \\
\hline Yes & $0(0.0)$ & $4(0.3)$ & & $0(0.0)$ & $3(0.3)$ & $1(0.5)$ & \\
\hline Antidepressant medication & & & 0.612 & & & & 0.057 \\
\hline No & $40(100)$ & 1239 (99.4) & & $153(100)$ & 865 (99.1) & $221(100)$ & \\
\hline Yes & $0(0.0)$ & $8(0.6)$ & & $0(0.0)$ & $8(0.9)$ & $0(0.0)$ & \\
\hline
\end{tabular}

Values are presented as mean \pm standard deviation, median [interquartile range], or number (\%).

MET, metabolic equivalent of task; PA, physical activity. 
ed by height in meters squared.

Trained examiners administered a questionnaire on obstetric history, demographic factors, lifestyle factors, and medical history in face-to-face interviews.

Information on reproductive health, including menopausal status, defined as cessation of menstruation for a minimum of 1 consecutive year, and the number of pregnancies and their outcomes (childbirth, stillbirth, or abortion) were obtained based on participants' self-reports in face-to-face interviews. The postmenopausal period was calculated as the difference between the age at the time of examination and age at the time of menopause. Working status was classified as working or non-working. The non-working group included housewives, students, and unemployed individuals. Physical activity was assessed using the Korean version of the International Physical Activity Questionnaire standard to yield the metabolic equivalent of task (MET). Participants were classified into 3 groups according to the MET score: inactive, minimally active, and health-enhancing physical activity. Participants were categorized according to their cigarette smoking status as ever-smokers (current or ex-smokers) and non-smokers (never smokers). Drinking status was categorized into "yes" (current alcohol drinkers and former drinkers) and "no" (non-drinkers). Marital status was divided into "unmarried" (never married, divorced, widowed, separated) and "married" (married and living with spouse). Education level was divided into middle school or less, high school, and university or beyond. Household income was classified into tertiles. A history of comorbidities, such as diabetes, hypertension, thyroid disease, and chronic kidney disease, was identified based on self-reported physician's diagnoses. Current information about antidepressant and antiosteoporotic medication use was also obtained from participants'self-reports.

The history of parity was obtained from participants who had been pregnant using the question, "How many total birth experiences have you had?" Participants were divided into four groups (nullipara, 1, 2,3+) based on parity. Because there were only 17 participants with a parity of 4 or higher, they were merged into the $3+$ category.

\section{Statistical Analysis}

Regression modeling was used to assess the associations between the predictors and LBD. First, we examined the difference in LBD between non-parous women (nullipara) and parous women using unadjusted and adjusted logistic regression models. We then examined the association between parity and LBD among parous women using unadjusted and adjusted logistic regression models. Age, BMl, postmenopausal period, working status, educational level, household income, marital status, smoking and alcohol intake, physical activity, and medical history were included as covariates in the adjusted models. We also performed a sensitivity analysis that restricted the outcomes only to osteoporosis using the fully adjusted model, as well as a subgroup analysis of the risk of LBD according to parity stratified by age group in tertiles. We additionally fitted generalized linear regression models to assess the association between parity and lumbar trabecular BMD $\left(\mathrm{mg} / \mathrm{cm}^{3}\right)$ as a continuous variable. Data analysis was performed from January to December 2020 using SAS version 9.4 (SAS Institute Inc., Cary, NC, USA).

\section{Ethics Statement}

The study protocol was approved by the Institutional Review Board of the Yonsei University College of Medicine (42013-0661)

\section{RESULTS}

The characteristics according to parity group are shown in Table 1. The mean age of the participants was 57.1 years. Only 40 (3.1\%) women were nullipara, 153 (11.9\%) were primipara, and 1094 (85.0\%) were multipara.

We first evaluated the difference in LBD risk between nulliparous and parous women, but there was no significant differ-

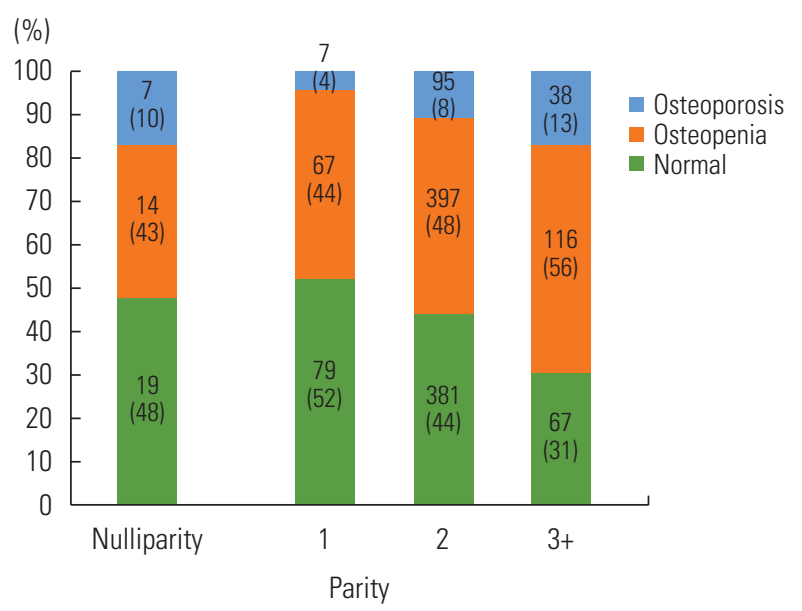

Figure 1. Frequency of osteopenia and osteoporosis of the lumbar spine in each parity group. Values are presented as number (\%). 
Table 2. Factors associated with LBD in parous postmenopausal women

\begin{tabular}{|c|c|c|c|c|}
\hline Factors & $\mathbf{n}$ & LBD, n (\%) & Unadjusted & Adjusted $^{1}$ \\
\hline Age (y) & 1247 & $720(57.7)$ & $1.16(1.13,1.20)$ & $1.12(1.08,1.17)$ \\
\hline Body mass index $\left(\mathrm{kg} / \mathrm{m}^{2}\right)$ & 1247 & $720(57.7)$ & $1.02(0.99,1.06)$ & $1.00(0.96,1.04)$ \\
\hline Postmenopausal period (y) & 1247 & $720(57.7)$ & $1.10(1.07,1.13)$ & $1.04(1.01,1.07)$ \\
\hline No. of abortions & 1247 & $720(57.7)$ & $1.02(0.93,1.12)$ & $0.99(0.90,1.09)$ \\
\hline \multicolumn{5}{|l|}{ Parity } \\
\hline 1 & 153 & $74(48.4)$ & 1.00 (reference) & 1.00 (reference) \\
\hline 2 & 873 & $492(56.4)$ & $1.38(0.98,1.95)$ & $1.40(0.97,2.02)$ \\
\hline$\geq 3$ & 221 & $154(69.7)$ & $2.45(1.60,3.76)$ & $1.95(1.23,3.09)$ \\
\hline \multicolumn{5}{|l|}{ PA (MET score) } \\
\hline Inactive & 304 & $185(60.9)$ & $1.17(0.85,1.60)$ & $1.18(0.84,1.66)$ \\
\hline Minimally active & 603 & $341(56.6)$ & $0.98(0.75,1.28)$ & $1.00(0.75,1.33)$ \\
\hline Health enhancing PA & 340 & $194(57.1)$ & 1.00 (reference) & 1.00 (reference) \\
\hline \multicolumn{5}{|l|}{ Education level } \\
\hline Middle school or less & 314 & $223(71.0)$ & $2.53(1.84,3.48)$ & $2.09(1.47,2.97)$ \\
\hline High school & 569 & $318(55.9)$ & $1.31(1.01,1.71)$ & $1.38(1.05,1.83)$ \\
\hline University or beyond & 364 & $179(49.2)$ & 1.00 (reference) & 1.00 (reference) \\
\hline \multicolumn{5}{|l|}{ Working status } \\
\hline Working & 612 & $341(55.7)$ & $0.85(0.68,1.06)$ & $1.03(0.81,1.33)$ \\
\hline Non-working & 635 & $379(59.7)$ & 1.00 (reference) & 1.00 (reference) \\
\hline \multicolumn{5}{|l|}{ Household income } \\
\hline Low & 157 & $86(54.8)$ & $0.83(0.57,1.21)$ & $0.97(0.64,1.48)$ \\
\hline Middle-low & 745 & $429(57.6)$ & $0.93(0.72,1.20)$ & $1.02(0.77,1.37)$ \\
\hline Middle-high/high & 345 & $205(59.4)$ & 1.00 (reference) & 1.00 (reference) \\
\hline \multicolumn{5}{|l|}{ Smoking } \\
\hline No & 1203 & $692(57.5)$ & 1.00 (reference) & 1.00 (reference) \\
\hline Ever & 44 & $28(63.6)$ & $1.29(0.69,2.41)$ & $1.53(0.76,3.06)$ \\
\hline \multicolumn{5}{|l|}{ Drinking } \\
\hline No & 430 & $271(63.0)$ & 1.00 (reference) & 1.00 (reference) \\
\hline Yes & 817 & $449(55.0)$ & $0.72(0.56,0.91)$ & $0.71(0.55,0.91)$ \\
\hline \multicolumn{5}{|l|}{ Marital status } \\
\hline Married & 1055 & $601(57.0)$ & 1.00 (reference) & 1.00 (reference) \\
\hline Unmarried & 192 & $119(62.3)$ & $1.23(0.90,1.69)$ & $1.19(0.84,1.68)$ \\
\hline \multicolumn{5}{|l|}{ Diabetes } \\
\hline No & 1181 & $675(57.2)$ & 1.00 (reference) & 1.00 (reference) \\
\hline Yes & 66 & $45(68.2)$ & $1.61(0.95,2.73)$ & $1.21(0.67,2.17)$ \\
\hline \multicolumn{5}{|l|}{ Hypertension } \\
\hline No & 987 & $573(58.1)$ & 1.00 (reference) & 1.00 (reference) \\
\hline Yes & 260 & $147(56.5)$ & $0.94(0.71,1.24)$ & $0.75(0.55,1.03)$ \\
\hline \multicolumn{5}{|l|}{ Thyroid disease } \\
\hline No & 1112 & $642(57.7)$ & 1.00 (reference) & 1.00 (reference) \\
\hline Yes & 135 & 78 (57.8) & $1.00(0.70,1.44)$ & $1.07(0.73,1.58)$ \\
\hline \multicolumn{5}{|l|}{ Chronic kidney disease } \\
\hline No & 1243 & $717(57.7)$ & 1.00 (reference) & 1.00 (reference) \\
\hline Yes & 4 & $3(75.0)$ & $2.20(0.23,21.17)$ & $1.62(0.17,15.86$ \\
\hline \multicolumn{5}{|l|}{ Antidepressant medication } \\
\hline No & 1239 & $716(57.8)$ & 1.00 (reference) & 1.00 (reference) \\
\hline Yes & 8 & $4(50.0)$ & $0.73(0.18,2.93)$ & $0.67(0.14,3.06)$ \\
\hline
\end{tabular}

Values are presented as odds ratio (95\% confidence interval).

LBD, low bone density; MET, metabolic equivalent of task; PA, physical activity.

${ }^{1}$ Adjusted for other variables in the table. 


\section{Journal of}

Table 3. Factors associated with osteoporosis in parous postmenopausal women

\begin{tabular}{|c|c|c|c|c|}
\hline Factors & n & With osteoporosis, n (\%) & Unadjusted & Adjusted $^{1}$ \\
\hline Age (y) & 1247 & $140(11.2)$ & $1.21(1.15,1.28)$ & $1.18(1.10,1.26)$ \\
\hline Body mass index $\left(\mathrm{kg} / \mathrm{m}^{2}\right)$ & 1247 & $140(11.2)$ & $1.01(0.96,1.07)$ & $0.99(0.93,1.06)$ \\
\hline Postmenopausal period (y) & 1247 & $140(11.2)$ & $1.08(1.05,1.11)$ & $1.02(0.99,1.07)$ \\
\hline No. of abortions & 1247 & $140(11.2)$ & $1.05(0.92,1.21)$ & $1.00(0.87,1.15)$ \\
\hline \multicolumn{5}{|l|}{ Parity } \\
\hline 1 & 153 & $7(4.6)$ & 1.00 (reference) & 1.00 (reference) \\
\hline 2 & 873 & $95(10.9)$ & $2.55(1.16,5.59)$ & $2.46(1.10,5.50)$ \\
\hline$\geq 3$ & 221 & $38(17.2)$ & $4.33(1.88,9.97)$ & $3.08(1.30,7.30)$ \\
\hline \multicolumn{5}{|l|}{ PA (MET score) } \\
\hline Inactive & 304 & $38(12.5)$ & $1.04(0.65,1.67)$ & $1.05(0.64,1.73)$ \\
\hline Minimally active & 603 & $61(10.1)$ & $0.82(0.54,1.25)$ & $0.85(0.55,1.33)$ \\
\hline Health enhancing PA & 340 & $41(12.1)$ & 1.00 (reference) & 1.00 (reference) \\
\hline \multicolumn{5}{|l|}{ Education level } \\
\hline Middle school or less & 314 & $51(16.2)$ & $1.82(1.15,2.89)$ & $1.45(0.86,2.42)$ \\
\hline High school & 569 & $54(9.5)$ & $0.99(0.63,1.54)$ & $1.04(0.65,1.66)$ \\
\hline University or beyond & 364 & $35(9.6)$ & 1.00 (reference) & 1.00 (reference) \\
\hline \multicolumn{5}{|l|}{ Working status } \\
\hline Working & 612 & $62(10.1)$ & $0.81(0.57,1.15)$ & $1.09(0.74,1.60)$ \\
\hline Non-working & 635 & $78(12.3)$ & 1.00 (reference) & 1.00 (reference) \\
\hline \multicolumn{5}{|l|}{ Household income } \\
\hline Low & 157 & $21(13.4)$ & $1.21(0.69,2.14)$ & $1.43(0.76,2.68)$ \\
\hline Middle-low & 745 & $80(10.7)$ & $0.94(0.63,1.42)$ & $1.05(0.68,1.64)$ \\
\hline Middle-high/ high & 345 & $39(11.3)$ & 1.00 (reference) & 1.00 (reference) \\
\hline \multicolumn{5}{|l|}{ Smoking } \\
\hline No & 1203 & $132(11.0)$ & 1.00 (reference) & 1.00 (reference) \\
\hline Ever & 44 & $8(18.2)$ & $1.80(0.82,3.96)$ & $2.66(1.10,6.46)$ \\
\hline \multicolumn{5}{|l|}{ Drinking } \\
\hline No & 430 & $58(13.5)$ & 1.00 (reference) & 1.00 (reference) \\
\hline Yes & 817 & $82(10.0)$ & $0.72(0.50,1.02)$ & $0.74(0.51,1.07)$ \\
\hline \multicolumn{5}{|l|}{ Marital status } \\
\hline Married & 1055 & $121(11.5)$ & 1.00 (reference) & 1.00 (reference) \\
\hline Unmarried & 192 & $19(9.9)$ & $0.85(0.51,1.41)$ & $0.77(0.44,1.34)$ \\
\hline \multicolumn{5}{|l|}{ Diabetes } \\
\hline No & 1181 & $130(11.0)$ & 1.00 (reference) & 1.00 (reference) \\
\hline Yes & 66 & $10(15.2)$ & $1.44(0.72,2.90)$ & $0.95(0.44,2.01)$ \\
\hline \multicolumn{5}{|l|}{ Hypertension } \\
\hline No & 987 & $104(10.5)$ & 1.00 (reference) & 1.00 (reference) \\
\hline Yes & 260 & $36(13.8)$ & $1.37(0.91,2.05)$ & $1.20(0.77,1.87)$ \\
\hline \multicolumn{5}{|l|}{ Thyroid disease } \\
\hline No & 1112 & $127(11.4)$ & 1.00 (reference) & 1.00 (reference) \\
\hline Yes & 135 & $13(9.6)$ & $0.83(0.45,1.51)$ & $0.89(0.47,1.66)$ \\
\hline \multicolumn{5}{|l|}{ Chronic kidney disease } \\
\hline No & 1243 & $139(11.2)$ & 1.00 (reference) & 1.00 (reference) \\
\hline Yes & 4 & $1(25.0)$ & $2.65(0.27,25.63)$ & $2.02(0.20,20.59)$ \\
\hline \multicolumn{5}{|l|}{ Antidepressant medication } \\
\hline No & 1239 & $139(11.2)$ & 1.00 (reference) & 1.00 (reference) \\
\hline Yes & 8 & $1(12.5)$ & $1.13(0.14,9.26)$ & $1.06(0.11,10.05)$ \\
\hline
\end{tabular}

Values are presented as odds ratio (95\% confidence interval).

MET, metabolic equivalent of task; PA, physical activity.

${ }^{1}$ Adjusted for other variables in the table. 
ence ( $p=0.502$ ) (Supplemental Material 1). Since non-parous women may have a history of pregnancy and abortion, we excluded nulliparous women from the following analysis to estimate $L B D$ risk according to parity.

Women in the higher parity group had lower educational levels $(p<0.001)$, a higher proportion of non-working status $(p=0.002)$, and higher proportion with non-drinking status $(p=0.032)$. These results could be explained by the fact that a higher number of older women were included in the higher parity group. The prevalence of LBD was 53\% (10\% osteoporosis $+43 \%$ osteopenia) among non-parous women; the prevalence increased gradually according to parity among parous women: $48 \%$ (4\% osteoporosis $+44 \%$ osteopenia) for a parity of 1,56\% (8\% osteoporosis $+48 \%$ osteopenia) for a parity of 2 , and $69 \%$ ( $13 \%$ osteoporosis $+56 \%$ osteopenia) for a parity of $3+$ (Figure 1).

The factors associated with LBD in the parous groups are shown in Table 2. The multivariable analysis revealed that compared to a parity of 1 , the risk of LBD increased by 1.40 times and 1.95 times for parities of 2 and $3+$, respectively. Older age, longer postmenopausal period, lower education level, and non-drinking status were also significantly associated with LBD in both the unadjusted and adjusted models (Table 2).

When we limited the outcome to osteoporosis, similar but stronger associations were observed between parity number and LBD; the odds ratio (95\% confidence interval) was 2.46 (1.10 to 5.50$)$ for a parity of 2 and 3.08 (1.30 to 7.30 ) for a parity of $3+$ relative to a parity of 1 (Table 3 ).

We examined the association between parity and LBD in

Table 4. Associations between parity and low bone density (LBD) according to age group

\begin{tabular}{lcrrcc}
\hline Age (y) & Parity & n & LBD, $\mathbf{n}(\%)$ & Unadjusted & Adjusted $^{1}$ \\
\hline $40-55$ & 1 & 60 & $20(33.3)$ & 1.00 (reference) & 1.00 (reference) \\
& 2 & 308 & $135(43.8)$ & $1.56(0.87,2.79)$ & $1.82(0.99,3.35)$ \\
& $\geq 3$ & 56 & $30(53.6)$ & $2.31(1.09,4.89)$ & $2.85(1.28,6.31)$ \\
$56-59$ & 1 & 49 & $26(53.1)$ & $1.00($ reference) & 1.00 (reference) \\
& 2 & 346 & $198(57.2)$ & $1.18(0.65,2.16)$ & $1.25(0.66,2.36)$ \\
& $\geq 3$ & 69 & $49(71.0)$ & $2.17(1.01,4.66)$ & $2.38(1.05,5.40)$ \\
$60-64$ & 1 & 44 & $28(63.6)$ & $1.00($ reference) & 1.00 (reference) \\
& 2 & 219 & $159(72.6)$ & $1.52(0.77,3.00)$ & $1.47(0.71,3.05)$ \\
& $\geq 3$ & 96 & $75(78.1)$ & $2.04(0.93,4.46)$ & $1.44(0.61,3.37)$ \\
\hline
\end{tabular}

Values are presented as odds ratio ( $95 \%$ confidence interval).

${ }^{1}$ Adjusted for age; body mass index; postmenopausal period; working status; education level; household income; marital status; smoking and drinking habits; physical activity; medical history including diabetes, hypertension, thyroid disease, chronic kidney disease; and antidepressant medication.
3 subgroups stratified by age. In women aged $40-55$ years and 56-59 years, similar to the trend for participants of all ages before stratification, women with higher parity had a higher risk of LBD. However, this trend was less significant in the older group (age 60-64 years), although we did not find a significant interaction between age group and parity ( $p=0.797)$ (Table 4). Since some studies reported that the risk of LBD increases exponentially with age, we conducted another sensitivity analysis with a model including age [2] but did not find different results (Supplemental Materials 2 and 3).

\section{DISCUSSION}

We found no significant difference in LBD between non-parous and parous women, but observed that higher parity was associated with a higher risk of LBD among parous women.

Previous studies have also suggested that women with higher parity have a higher risk of LBD. A previous study evaluated the influence of parity on BMD and the risk of postmenopausal fracture and found that women with higher parity had significantly lower lumbar and femoral BMD after adjusting for age and BMI [15]. In another study, it was revealed that femoral BMD significantly decreased as parity increased, although no significant differences were found in the frequency of lumbar osteoporosis in the study group [16].

Some explanations have been proposed for the dose-relationship between parity and LBD. The recovery of bone density loss accelerates with the resumption of menstruation that was interrupted during pregnancy and breastfeeding. Women who experience repeated pregnancy, as well as women who have a short interval between pregnancies, have insufficient time to recover BMD as the number of pregnancies increases. In fact, pregnancy interval and number of pregnancies are independent factors associated with bone recovery, not breastfeeding [1]. This could explain the result that the risk of LBD increased depending on parity among parous women in our study.

We hypothesized that women with high parity may neglect aspects of lifestyle management, such as physical activity and nutrition, during parenting, which may increase the risk of LBD. However, in our study, having a high number of live births was not significantly associated with lower physical activity or higher BMI.

Since age was significantly and independently associated with decreased BMD [17], it is very important to consider age; 
however, an age-stratified association was not conducted in previous studies. In the fully adjusted model of the subgroup analysis following stratification into age tertiles, the intensity of the association between LBD and parity in the older age group was slightly diminished compared to the intensity in the other younger age groups. One possible explanation is a cohort effect. Each age group consisted of Korean women born between the 1950s and 1970s. During this period, Korea experienced sudden social changes immediately after the Korean war, such that women in each age group had quite different early life experiences; this could have affected their BMD according to their time of birth.

Nulliparous women have a heterogeneous background of not giving birth. Since various characteristics in nulliparous women are different from those in parous women, nulliparous women were excluded from the main analysis to estimate the risk of LBD according to parity.

The present study has some limitations. First, there was no breastfeeding history information in the data. Pregnancy and lactation affect bone metabolism and calcium homeostasis; during this period, increased intestinal calcium absorption and breast milk secretion cause calcium loss from the maternal skeleton, but bone loss could be restored within 6-12 months after weaning $[1,18,19]$. During 6 months following exclusive lactation and despite continued lactation, spinal BMD was found to increase significantly in a previous study [7]. Several recent studies have concluded that there is no significant association between decreased BMD and lactation, and that lactation does not increase the risk of fracture [19]. Therefore, it is believed that the significance of the effect of parity on LBD would not change if breastfeeding history had been included. Second, misclassification of parity was possible because women's reproductive history was collected based on self-reports. Moreover, women's reproductive information, such as that regarding abortions and pregnancies, may not be accurate because of a tendency for low rates of obstetric and gynecologic visits during pregnancy. Third, the CMERC cohort comprised a middle-aged (30-64 years) study population with no participants aged $\geq 65$ years. Therefore, in this study, we could not analyze the risk of LBD according to parity number in older women, who have a high prevalence of osteoporosis and osteopenia. Fourth, there is a lack of generalizability when we compare the prevalence of LBD in our sample with a nationwide study sample. The prevalence of LBD in this study was lower than that in a 2008-2011 nationwide study for the 50- year to 59-year age group in each sample (CMERC: women aged 50-59 years: osteopenia $44.3 \%+o s t e o p o r o s i s ~ 8.1 \%$; KNHANES: women aged 50-59 years: osteopenia 58.6\%+osteoporosis 15.4\%) [2]. The lower prevalence of LBD in our study can be explained by the fact that BMD measured using DXA tends to be overestimated compared to the BMD measured using QCT, as in our study, and that our study sample comprised relatively healthy people. Lastly, calcium intake was not adjusted for the association between LBD and parity in this study. Calcium is an essential element in the diet, but its role in the pathogenesis of osteoporosis remains controversial [20]. In this study, daily calcium intake was not significantly associated with LBD (age-adjusted $p$-value $=0.453$ ). Based on previous literature and our analysis results, daily calcium intake was not included in the final model.

The main result of our analysis is that higher parity was associated with a higher risk of LBD in postmenopausal Korean women who had given birth. In particular, LBD of weightbearing bones can lead to compression fractures. Accordingly, BMD monitoring is needed to detect LBD at an early stage and perform pharmacological and non-pharmacological interventions among postmenopausal women in Korea who have experienced multiple births.

In conclusion, we found a dose-related association between parity and LBD in Korean postmenopausal parous women. This association remained after adjusting for potential confounding covariates. Future studies should examine the longitudinal association between parity and the risk of developing osteoporosis and osteoporotic fractures.

\section{SUPPLEMENTAL MATERIALS}

Supplemental materials are available at https://doi.org/10. 3961/jpmph.21.162.

\section{CONFLICT OF INTEREST}

The authors have no conflicts of interest associated with the material presented in this paper.

\section{FUNDING}

This study was supported by a grant (HI13C0715) from the Korea Health Technology R\&D Project, funded by the Ministry of Health and Welfare of the Republic of Korea. 


\section{ACKNOWLEDGEMENTS}

None.

\section{AUTHOR CONTRIBUTIONS}

Conceptualization: ES, HCK. Data curation: ES, HCK, YL. Formal analysis: ES, HCK. Funding acquisition: HCK. Methodology: ES, HCK. Visualization: ES, HCK, YL. Writing - original draft: ES, HCK. Writing - review \& editing: ES, HCK, YL.

\section{ORCID}

$\begin{array}{ll}\text { Eunsun Seo } & \text { https://orcid.org/0000-0002-5035-8364 } \\ \text { Youngrong Lee } & \text { https://orcid.org/0000-0003-1367-4381 } \\ \text { Hyeon Chang Kim } & \text { https://orcid.org/0000-0001-7867-1240 }\end{array}$

\section{REFERENCES}

1. Yan G, Huang Y, Cao H, Wu J, Jiang N, Cao X. Association of breastfeeding and postmenopausal osteoporosis in Chinese women: a community-based retrospective study. BMC Womens Health 2019;19(1):110.

2. Park EJ, Joo IW, Jang MJ, Kim YT, Oh K, Oh HJ. Prevalence of osteoporosis in the Korean population based on Korea National Health and Nutrition Examination Survey (KNHANES), 20082011. Yonsei Med J 2014;55(4):1049-1057.

3. Pasco JA, Seeman E, Henry MJ, Merriman EN, Nicholson GC, Kotowicz MA. The population burden of fractures originates in women with osteopenia, not osteoporosis. Osteoporos Int 2006;17(9):1404-1409.

4. Park C, Ha YC, Jang S, Jang S, Yoon HK, Lee YK. The incidence and residual lifetime risk of osteoporosis-related fractures in Korea. J Bone Miner Metab 2011;29(6):744-751.

5. Hwang IR, Choi YK, Lee WK, Kim JG, Lee IK, Kim SW, et al. Association between prolonged breastfeeding and bone mineral density and osteoporosis in postmenopausal women: KNHANES 2010-2011. Osteoporos Int 2016;27(1):257-265.

6. Lee EN. Effects of parity and breastfeeding duration on bone density in postmenopausal women. Asian Nurs Res (Korean Soc Nurs Sci) 2019;13(2):161-167.

7. Cooke-Hubley S, Kirby BJ, Valcour JE, Mugford G, Adachi JD, Kovacs CS. Spine bone mineral density increases after 6 months of exclusive lactation, even in women who keep breastfeeding.
Arch Osteoporos 2017;12(1):73.

8. More C, Bettembuk P, Bhattoa HP, Balogh A. The effects of pregnancy and lactation on bone mineral density. Osteoporos Int 2001;12(9):732-737.

9. Crandall CJ, Liu J, Cauley J, Newcomb PA, Manson JE, Vitolins $M Z$, et al. Associations of parity, breastfeeding, and fractures in the Women's Health Observational Study. Obstet Gynecol 2017;130(1):171-180.

10. Wang Q, Huang Q, Zeng Y, Liang JJ, Liu SY, Gu X, et al. Parity and osteoporotic fracture risk in postmenopausal women: a dose-response meta-analysis of prospective studies. Osteoporos Int 2016;27(1):319-330.

11. Song SY, Kim Y, Park H, Kim YJ, Kang W, Kim EY. Effect of parity on bone mineral density: a systematic review and meta-analysis. Bone 2017; 101:70-76.

12. Ma XH, Zhang W, Wang Y, Xue P, Li YK. Comparison of the spine and hip BMD assessments derived from quantitative computed tomography. Int J Endocrinol 2015;2015:675340.

13. Li N, Li XM, Xu L, Sun WJ, Cheng XG, Tian W. Comparison of QCT and DXA: osteoporosis detection rates in postmenopausal women. Int J Endocrinol 2013;2013:895474.

14. American College of Radiology. ACR-SPR-SSR practice parameter for the performance of musculoskeletal quantitative computed tomography (QCT); 2018 [cited 2021 Mar 1]. Available from: https://www.acr.org/-/media/ACR/Files/PracticeParameters/qct.pdf.

15. Allali F, Maaroufi H, Aichaoui SE, Khazani H, Saoud B, Benyahya $B$, et al. Influence of parity on bone mineral density and peripheral fracture risk in Moroccan postmenopausal women. Maturitas 2007;57(4):392-398.

16. Peker N, Tosun ÖÇ. Is grand multiparity a risk factor for the development of postmenopausal osteoporosis? Clin Interv Aging 2018;13:505-508.

17. Kritz-Silverstein D, Barrett-Connor E, Hollenbach KA. Pregnancy and lactation as determinants of bone mineral density in postmenopausal women. Am J Epidemiol 1992;136(9):10521059.

18. Kalkwarf HJ, Specker BL. Bone mineral loss during lactation and recovery after weaning. Obstet Gynecol 1995;86(1):26-32.

19. López JM, González G, Reyes V, Campino C, Díaz S. Bone turnover and density in healthy women during breastfeeding and after weaning. Osteoporos Int 1996;6(2):153-159.

20. Reid IR, Bristow SM, Bolland MJ. Calcium supplements: benefits and risks. J Intern Med 2015;278(4):354-368. 